\title{
Bank Credit Financing and Trade Credit Financing Based on Carbon Emission Trading
}

\author{
Hao Sun (iD) and Guangkuo Gao \\ Business School, University of Shanghai for Science and Technology, Shanghai 200093, China \\ Correspondence should be addressed to Hao Sun; 705143946@qq.com
}

Received 25 November 2021; Revised 26 December 2021; Accepted 3 January 2022; Published 19 January 2022

Academic Editor: Arunava Majumder

Copyright (C) 2022 Hao Sun and Guangkuo Gao. This is an open access article distributed under the Creative Commons Attribution License, which permits unrestricted use, distribution, and reproduction in any medium, provided the original work is properly cited.

\begin{abstract}
Bank credit financing and trade credit financing are two basic ways for small- and medium-sized enterprises to solve financial difficulties. We studied a supply chain financing (SCF) system with one capital-constrained manufacturer and one capital-rich supplier, in which manufacturers can choose bank credit financing (BCF) or trade credit financing (TCF) to solve financial difficulties. Unlike the traditional SCF, we considered the influence of the carbon emission trading mechanism, and we designed BCF and TCF models and derived the equilibrium strategies of the supply chain members under a carbon-constrained environment. The research shows that the emission reduction level of manufacturers increases with the increase in carbon emission trading price, and the output of manufacturers increases with the increase in emission reduction level of manufacturers. When the manufacturer's emission reduction level is low, the supplier's benefits under BCF are higher than those under TCF. There is a threshold for the manufacturer's emission reduction level. When the emission reduction level is higher than this threshold, the manufacturer chooses BCF mode with higher benefits; on the contrary, TCF mode is more profitable.
\end{abstract}

\section{Introduction}

In the past decade, climate change caused by carbon emissions has received great attention from countries around the world. Many countries and regions have promulgated various policies to limit carbon emissions to control carbon emissions, among which the policy of carbon emission trading is most widely used. Carbon emission trading refers to the enterprises in the same industry; if the actual carbon emission of the enterprise is lower than the government quota through increasing research and technological innovation, the enterprise can sell the extra quota in the market to gain profits; on the contrary, if an enterprise's carbon emissions exceed the quota, it needs to buy the remaining quota of other enterprises in the market to continue production [1]. Carbon emission trading policy encourages enterprises to save energy and reduce emissions from the perspective of trading. In 1997, the United Nations Climate Convention adopted the Kyoto Protocol, which for the first time set targets for controlling greenhouse gas emissions. In 2005, the European Union established the carbon emission trading system and began to implement the carbon cap-and-trade mechanism. After the 2015 Paris Agreement Summit, the United States, Australia, China, and other countries have established carbon trading market systems and formulated relevant carbon emission permit trading policies.

Under the pressure of the government's carbon emission regulation, many enterprises are facing great pressure on environmental protection. Low-carbon production can help enterprises avoid being punished for environmental pollution and achieve a win-win goal of environmental protection and profits [2]; however, many enterprises, especially smalland medium-sized enterprises, usually face capital constraints, which will be more severe when they make a lowcarbon investment. Therefore, enterprises need to conduct external financing to achieve low-carbon emission reduction and production goals.

Generally, there are two main ways for enterprises to obtain funds: bank credit financing and trade credit 
financing. Bank credit financing (BCF) is the most widely used financing method at present. Under the bank credit financing mode, enterprises obtain funds from banks in the form of asset collateral. At the end of the period, the enterprise pays back the principal and interest of the loan to the bank; if the enterprise cannot be repaid, the bank will confiscate the assets mortgaged by the enterprise and the enterprise will go bankrupt. The assets, such as raw materials or finished products, which are mortgaged by an enterprise, cannot be used for production or sold during the period of the mortgage. Therefore, BCF mode will produce certain financial risk costs and opportunity costs for enterprises [3]. Trade credit financing (TCF) is a unique financing model in the context of supply chain trade. Under the trade credit financing (TCF) model, suppliers are both investors and operators, which can share financial risk pressure for manufacturers, and manufacturers can also avoid bankruptcy risk caused by capital shortage [4]. However, suppliers will also share some of the profits of the manufacturer, thus reducing the profit level of the manufacturer. Then, under the two financing modes, how do the manufacturer's optimal output, the optimal emission reduction level, and the supplier's optimal wholesale price change? How should manufacturers choose between the two financing modes, and what is the impact on the income of all parties? This is the problem that needs to be studied deeply at present.

Based on the above analysis, we consider the influence of the carbon emission trading mechanism, and we designed BCF and TCF models and derived the equilibrium strategies of the supply chain members under a carbon-constrained environment. Through research, we found that the emission reduction level of manufacturers increases with the increase in carbon emission trading price, and the output of manufacturers increases with the increase in emission reduction level of manufacturers. When the manufacturer's emission reduction level is low, the supplier's benefits under BCF are higher than those under TCF. There is a threshold for the manufacturer's emission reduction level. When the emission reduction level is higher than this threshold, the manufacturer chooses BCF mode with higher benefits; on the contrary, TCF mode is more profitable.

The research innovation of this study is summarized as follows. First, we analyzed the carbon emission reduction and ordering decisions of cash-strapped manufacturers to consider the impact of carbon emission trading. Second, considering the uncertainty of consumer demand, we combine consumer demand with supply chain operation financing to analyze the optimal decision of supply chain members. Third, we compared GCF and TCF modes to analyze the effectiveness and applicability of the two financing modes in supply chain operation.

The remainder of this study is organized as follows. In Section 2, we review the related literature. In Section 3, we describe the research problems and put forward some assumptions about the application of the model. In Section 4, we make an equilibrium analysis of two financing modes. In Section 5, we compare and analyze the effectiveness and applicability of BCF and TCF. In Section 6, we conduct a series of numerical analyses to compare the performance of the supply chain under the two financing modes. Section 7 summarizes the research conclusions and proposes the future research direction.

\section{Literature Review}

This study mainly involves two aspects of literature: (1) supply chain operation management under the carbon capand-trade mechanism and (2) bank credit financing and trade credit financing decisions under supply chain operation. The differences between this study and existing literature are highlighted by reviewing relevant literature.

In the study of operation management under carbon emission trading mechanism, Dobos et al. [5] analyzed the influence of carbon emission trading mechanism on enterprise production and inventory strategy using the dynamic Arrow-Karlin model. Zhang and Xu [1] proposed an efficient solution method with linear computational complexity to analyze the optimal production strategy under the constraints of carbon cap and trade. Qin et al. [6] studied the operation and coordination of the supply chain under the policy of carbon emission trading and compared it with the case without carbon emission constraint. Song et al. [7] studied the expansion of logistic capacity of enterprises under carbon emission trading regulations by constructing a two-stage stochastic model. Xu et al. [8] considered the influence of carbon cap and trade, deduced the optimal total emissions and optimal output of products, and analyzed the influence of emission trading price on optimal production decisions and optimal profits. Bai et al. [9] studied the influence of investment in green technology under carbon capand-trade rules on the coordination of the supply chain of deteriorated products. Mishra et al. [10] considered the influence of carbon cap and carbon trading mechanism to study a sustainable closed-loop supply chain of control waste and carbon emissions.

Through sorting out, we found that the above literature analyses the optimal decision of manufacturers' emission reduction investment based on the situation that manufacturers have enough capital. In practice, manufacturers' low-carbon emission reduction decisions are usually influenced by capital constraints, which are not considered in the above literature. Different from the above research, we mainly studied low-carbon investment and financing decisions of manufacturers with limited capital.

Another literature related to this study is financing decisions under supply chain operation. Supply chain financing (SCF) refers to the integration of financial concerns with supply chain members' operational decisions, and it is particularly important when firms face the problem of capital constraints. For example, considering the uncertainty of market demand, Jing et al. [11] used the newsvendor model to analyze the financing mode selection of capitalconstrained suppliers. Huang et al. [12] constructed a financing framework based on a supply chain benchmark contract considering the risks of financing subjects and, respectively, discussed the balance strategy of the supply chain under three financing modes. Cao et al. [13] found that if the pledge of carbon emission rights becomes a part of the 
financial and operational decisions of enterprises, carbon emission constraints may also become the source of corporate profits. Huang et al. [14] analyzed the influence of the financing guarantee mechanism provided by the buyer on the overall value of each participant and the supply chain in a supply chain. Yang et al. [15] studied how trade credit can improve supply chain efficiency by partially sharing demand risks between retailers and suppliers. Beka et al. [16] conducted a questionnaire survey among supply chain managers of 177 Chinese manufacturing enterprises to explore the effectiveness of supply chain finance applications.

Under such a setting, some scholars have compared different financing methods of capital-constrained enterprises in the supply chain. The most common financing methods are bank credit finance (BCF) and trade credit financing (TCF). For example, considering the bankruptcy cost demand uncertainty, Shi et al. [17] discussed the financing mode choice between bank credit financing and trade credit financing for retailers under capital constraints. Huang et al. [12] constructed a financing framework based on a supply chain benchmark contract considering the risks of financing subjects and, respectively, discussed the balance strategy of the supply chain under three financing modes. Kouvelis and Zhao [18] used the newsvendor model to analyze the choice of financing mode considering that both suppliers and retailers were constrained by capital. Cai et al. [19] studied the effects of bank credit and trade credit on capital-constrained retailers in the case of uncertain demand. In addition, some literature has studied mixed financing modes. For example, Li et al. [20] studied the operation decision of combining partial trade credit financing and partial credit guarantee financing. Zhou et al. [21] explored how retailers with capital constraints should choose financing modes by constructing three financing models of non-financing, bank financing, and mixed financing.

However, all the above studies focus on supply chain financing strategies under capital constraints and do not consider the influence of carbon emission trading mechanisms on the decision-making of supply chain members. To sum up, the above literature ignores the influence of carbon emission constraints or capital constraints on supply chain operation decisions.

In recent years, some scholars have begun to pay attention to the impact of trade credit finance on enterprise decision-making in the supply chain. For example, Mandal et al. [22] studied sustainable inventory management considering advertising and trade credit policies and derived the solution method for the existence of the global optimal solution. Sarkar et al. [23] considered the time-varying deterioration rate of products and studied the optimal replenishment decision for retailers with variable demand for deteriorating products under a trade credit policy. AHM Mashud et al. [24] studied a sustainable inventory system with the advanced payment policy and trade credit strategy for a two-warehouse inventory system considered a noninstantaneous deterioration. Ahmed et al. [25] developed a synergic inventory model to get the most profit by making an allowance for reworking, multi-period delay-in-payment policy, and shortages. The above literature considers the impact of trade credit finance on the inventory level of enterprises. Different from them, this study considers the impact of trade credit finance on enterprise emission reduction level and order quantity. Some scholars have studied the influence of trade credit from commodity pricing, such as Mashud et al. [26] who studied the retailer's joint pricing model through an effective preservation strategy under a trade credit policy, and they used a classical optimization technique to solve the model. Shaikh et al. [27] studied a decision support system to provide customers with trade credit financing considering two different selling prices. Singh et al. [28] assumed that demand is a function of credit period and sale price, and they studied the impact of supply chain management on energy and carbon emissions under a two-level trade credit policy. Unlike them, our study considers the impact of random demand fluctuation on enterprise financing decision-making and focuses on the choice of different financing models from the perspective of enterprises.

Some scholars have considered the influence of carbon emission constraints on supply chain financing strategies, and the most closely related to our research is An et al. [29]. They studied the financing strategy selection of green credit and trade credit under the constraint of carbon emission, and they added the hard constraint of carbon emission standards to the conditions for manufacturers to obtain green credit from banks. If the carbon emission exceeds the standard, the bank will terminate the loan business. On the other hand, when enterprises choose trade credit, they will not be limited by carbon emission in the beginning, but they will be penalized if their carbon emission exceeds the specified limit in the later stage. Different from the above research, this study introduces the carbon emission trading mechanism. If the manufacturer's carbon emissions exceed the quota, it can purchase the remaining quota of other enterprises through the carbon trading platform to continue production. Manufacturers can also sell excess carbon allowances for a profit. The research content and methods of this study supplement the research results of Simin et al. and provide theoretical reference for supply chain financing under the constraints of carbon emissions.

\section{Problem Description and Basic Assumptions}

3.1. Problem Description. This study studies a supply chain financing system composed of suppliers, manufacturers, and banks. Under the carbon emission trading mechanism, manufacturers purchase raw materials from suppliers and sell them to consumers after processing. In the process of supply chain operation, manufacturers in the lower reaches of the supply chain are often short of funds, while suppliers generally have more funds. Manufacturers can solve the problem of capital constraint in the process of ordering and emission reduction investment through BCF and TCF. In the bank credit mode, the manufacturer obtains loans from the bank through asset collateral, and in the trade credit mode, the manufacturer obtains financing from the supplier in the form of deferred payment. Suppliers and 
manufacturers form a game relationship. In the game, suppliers play a dominant role, while manufacturers play a follower role. Suppliers provide balanced wholesale prices to maximize profits and maintain cooperation with manufacturers.

For ease of representation, subscripts $B$ and $T$ represent the two cases under BCF and TCF, respectively, and subscripts $m$ and $s$ represent the manufacturer and supplier, respectively. Table 1 summarizes the meanings of symbols in this study. The framework of supply chain financing system is shown in Figure 1.

As the concept of green and low-carbon becomes popular, consumers are increasingly concerned about the low-carbon properties of products and tend to buy low-carbon products [30]. Therefore, in the process of product production and lowcarbon investment, manufacturers should consider the sensitivity of market demand to the low-carbon level of the product. So, the consumer demand function can be expressed as $D=\delta K_{t}+\varepsilon$, and $F(\varepsilon)$ and $f(\varepsilon)$ represent the probability distribution function and probability density function of market random demand, respectively.

The cost of carbon emission mainly includes two parts: first, the cost of buying a carbon emission permit that exceeds a government-set carbon emission limit. The cost depends mainly on the number of carbon emission permits to be purchased and the price of carbon trading; and second, the cost of investment in reducing emissions. It mainly includes the following: (1) the cost of technical research and equipment update, (2) reserves and interest retained by enterprises for energy conservation and emission reduction, (3) the cost of operation and maintenance of low-carbon emission reduction equipment, and (4) depreciation cost of low-carbon emission reduction equipment.

3.2. Basic Assumptions. Without losing generality, we make the following assumptions.

Hypothesis 1. Under the carbon emission trading mechanism, manufacturers can obtain a certain number of carbon emission rights from the government for free in the initial stage for product production. Manufacturers' carbon permits could be traded on a carbon market.

Hypothesis 2. As consumers have low-carbon preference, the low-carbon emission reduction level directly affects product demand, and manufacturers can increase consumers' purchase volume by increasing the low-carbon emission reduction level.

Hypothesis 3. The manufacturer's capital can pay for lowcarbon emission reduction investment, but not enough to pay for procurement costs and low-carbon investment.

Hypothesis 4. The manufacturer can choose either BCF or TCF. Under the BCF model, the manufacturer bears the cost of financial risk and opportunity cost, while under the TCF
TABLE 1: Summary of notations.

\begin{tabular}{lc}
\hline Notation & Definition \\
\hline$p$ & Unit selling price \\
$U$ & Carbon emission quota \\
$\tau$ & Low-carbon emission reduction cost coefficient \\
$w_{T}$ & Supplier wholesale price under TCF \\
$w_{B}$ & Supplier wholesale price under BCF \\
$K_{t B}$ & Manufacturer emission reduction level under BCF \\
$K_{t T}$ & Manufacturer emission reduction level under TCF \\
$c$ & Supplier's production cost \\
$\delta$ & Consumer low-carbon preference coefficient \\
$p_{e}$ & Carbon trading unit price \\
$R$ & Bank credit rate \\
$e$ & Carbon emissions per unit of product produced \\
$q_{T}$ & Manufacturer's order quantity under TCF \\
$q_{B}$ & Manufacturer's order quantity under BCF \\
$\varepsilon$ & Random variable \\
$\lambda$ & Revenue sharing proportion \\
\hline
\end{tabular}

model, the supplier shares part of the manufacturer's benefits.

Hypothesis 5. Manufacturer's order quantity and its production are consistent, and all parameters are the consensus of banking institutions, suppliers, and manufacturers.

For ease of representation, subscripts $B$ and $T$ represent the two cases under BCF and TCF, respectively, and subscripts $m$ and $s$ represent the manufacturer and supplier, respectively. Table 1 summarizes the meanings of symbols in this study, as follows.

\section{Financing Equilibrium Analysis}

4.1. Balance of BCF. Under BCF, manufacturers seek credit financing from banks because their funds cannot meet the demand for ordering and low-carbon investment. The specific process is as follows. At the beginning of the period, the supplier announces the wholesale price of the product $w_{B}$ to the manufacturer. After receiving the wholesale price of the product, the manufacturer decides ordering quantity $q_{B}$ and low-carbon investment level $K_{t B}$ considering the dual influence of carbon emission constraint and consumers' low-carbon preference. We assume that the ordering cost of the manufacturer is $w_{B} q_{B}$, the low-carbon investment cost is $1 / 2 \tau k_{t B}^{2}[13,31]$, and the total input cost of the manufacturer for production is $w_{B} q_{B}+1 / 2 \tau k_{t B}^{2}$. The sum of the financial risk cost and the opportunity cost of asset pledge is $r_{c}$; under the carbon emission trading mechanism, the capital flow generated by carbon trading by manufacturers can be expressed as $T=p_{e}\left[U-\left(e q_{B}-k_{t B}\right)\right]$; we assume that the initial capital of the manufacturer is $B$, which is insufficient to cover the ordering cost and low-carbon investment, and the amount of loan the manufacturer needs to borrow from the bank is $w_{B} q_{B}+1 / 2 \tau k_{t B}^{2}-B$. Therefore, under the BCF model, the manufacturer's revenue function can be expressed as follows: 


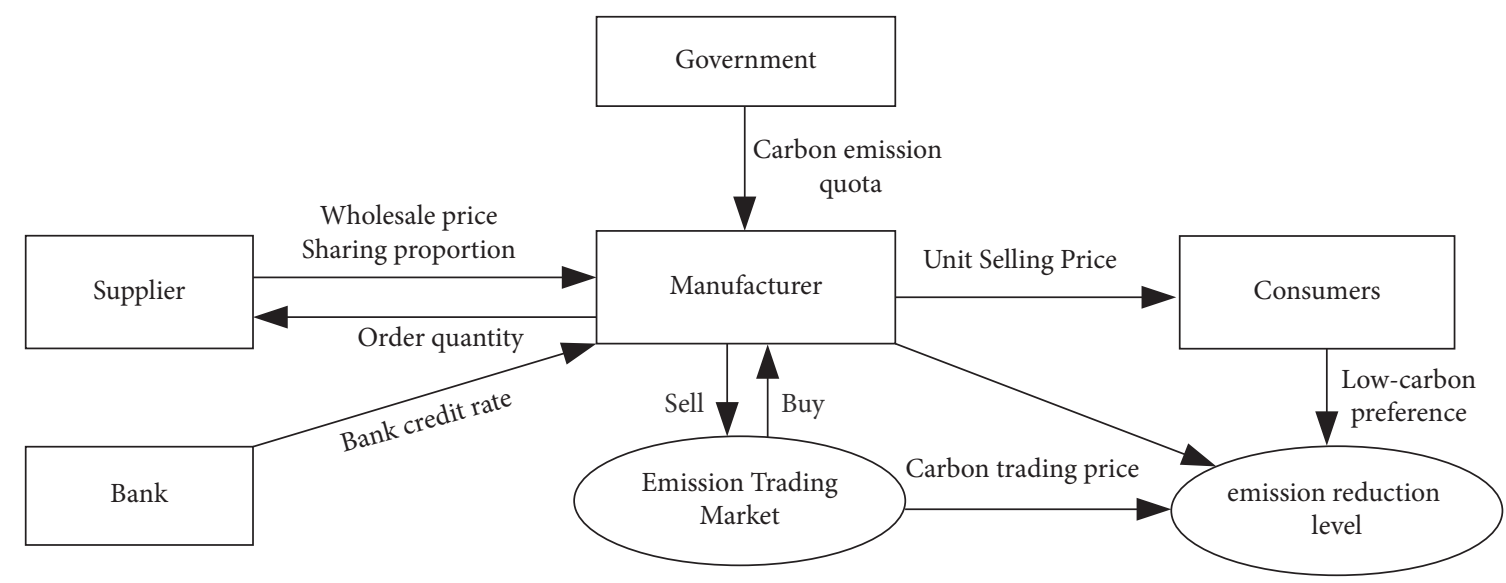

FIGURE 1: Framework of supply chain financing system.

$$
\pi_{B}^{m}=E\left[p \min \left\{D, q_{B}\right\}\right]+p_{e}\left[U-\left(e q_{B}-k_{t B}\right)\right]-\left(w_{B} q_{B}+\frac{1}{2} \tau k_{t B}^{2}-B\right)(1+R)-r_{c}
$$

Proposition 1. In BCF mode, when the supplier sets the wholesale price as $w_{B}$, the manufacturer's optimal order quantity and low-carbon emission reduction level can be obtained as follows:

$$
\left\{\begin{array}{l}
q_{B}^{*}=F^{-1}\left(\widehat{y}_{1}\right)+\delta k_{t B} \\
k_{t B}^{*}=\frac{\delta\left[p+p_{e} e-w_{B}(1+R)\right]+p_{e}}{\tau(1+R)}
\end{array}\right.
$$

where $\widehat{y}_{1}=p-p_{e} e-w_{B}(1+R) / p$.

Proof. According to equation (1), the expression of the manufacturer's revenue function can be rewritten as follows $[29,32]:$

$$
\pi_{B}^{m}=p\left[q_{B}-\int_{0}^{q_{B}-\delta k_{t B}} F(x) d x\right]-p_{e}\left(e q_{B}-k_{t B}-U\right)-\left(w_{B} q_{B}+\frac{1}{2} \tau k_{t B}^{2}-B\right)(1+R)-r_{c}
$$

Firstly, we take the first and second derivatives of $\pi_{B}^{m}$ with respect to $q_{B}$, and we have the following:

$$
\begin{aligned}
\frac{d \pi_{B}^{m}}{d q_{B}} & =p\left[1-F\left(q_{B}-\delta k_{t B}\right)\right]-p_{e} e-w_{B}(1+R), \\
\frac{d^{2} \pi_{B}^{m}}{d q_{B}^{2}} & =-p f\left(q_{B}-\delta k_{t B}\right) .
\end{aligned}
$$

Then, taking the first and second derivatives of $\pi_{B}^{m}$ with respect to $k_{t B}$, we can get the following:

$$
\begin{aligned}
\frac{d \pi_{B}^{m}}{d k_{t B}} & =p \delta F\left(q_{B}-\delta k_{t B}\right)+p_{e}-\tau k_{t B}(1+R), \\
\frac{d^{2} \pi_{B}^{m}}{d k_{t B}^{2}} & =-p \delta^{2} f\left(q_{B}-\delta k_{t B}\right)-\tau(1+R) .
\end{aligned}
$$

Finally, we take the derivative of $d \pi_{B}^{m} / d q_{B}$ with respect to $k_{t B}$, and we can get the following:

$$
\frac{\partial^{2} \pi_{B}^{m}}{\partial q_{B} \partial k_{t B}}=p \delta\left[f\left(q_{B}-\delta k_{t B}\right)\right]
$$

Thus, we have the determinant $H\left(q_{B}, k_{t B}\right)=p \tau f$ $\left(q_{B}-\delta k_{t B}\right)(1+R)>0$. From $d^{2} \pi_{B}^{m} / d q_{B}^{2}<0$ and $H\left(q_{B}, k_{t B}\right)$ $>0$, we can get that the Hessian matrices are negative definite, so we can judge that $\pi_{B}^{m}$ is jointly concave at points $q_{B}$ and $k_{t B}$. Therefore, let $d \pi_{B}^{m} / d q_{B}=0$ and $d \pi_{B}^{m} / d k_{t B}=0$, and we can obtain the manufacturer's optimal emission reduction level and order quantity.

From Proposition 1, we can see that the manufacturer's optimal order quantity is closely related to wholesale price, lowcarbon emission reduction level, and consumers' low-carbon preference coefficient. Manufacturers' low-carbon investment level is related to consumers' low-carbon preference coefficient, sale price, wholesale price, and carbon trading price.

Proposition 1 it indicates that when the supplier's wholesale price $w_{B}$ is high, the manufacturer will reduce the order quantity and low-carbon investment level and make a relatively conservative decision. Proposition 1 gives the manufacturer's optimal order quantity and emission reduction level for the supplier's wholesale price. 
The next step is to discuss the supplier's optimal wholesale price decision. We can express the supplier's expected revenue as follows:

$$
\pi_{B}^{s}=\left(w_{B}-c\right) q_{B} .
$$

The supplier, as the leader of Stackelberg, makes the decision first, and then, the manufacturer makes the decision. Based on backward induction, the supplier determines the optimal wholesale price according to the rational response of the manufacturer to the wholesale price. Thus, we can obtain the supplier's optimal wholesale price, as shown in Proposition 2.

Proposition 2. In BCF mode, the supplier's optimal wholesale price $w_{B}$ is as follows:

$$
w_{B}^{*}=c-\frac{p q_{B} F^{2}\left(\widehat{y}_{1}\right)}{(1+R) f\left(\widehat{y}_{1}\right)},
$$

where $\hat{y}_{1}=p-p_{e} e-w_{B}(1+R) / p$.

Proof. Taking the first partial derivative of equation (7) with respect to $w_{B}$, we can get the following:

$$
\frac{d \pi_{B}^{s}}{d w_{B}}=q_{B}+\left(w_{B}-c\right) \frac{d q_{B}}{d w_{B}} .
$$

Setting the value of equation (9) is equal to 0 and solving it, we can obtain the optimal value of wholesale price $w_{B}$.

From Proposition 2, we can see that the wholesale price of suppliers largely depends on the production cost and is also affected by the manufacturer's order quantity, product sale price, and bank credit rate. Proposition 2 shows that supplier's wholesale price is negatively correlated with product sale price and order quantity and positively correlated with bank interest rate.

4.2. Balance of TCF. Under the TCF, the manufacturers' initial capital can cover their low-carbon investments $\left(k>k_{t T}\right)$, but after manufacturers make low-carbon investments, the remaining funds are not enough to keep manufacturers ordering and producing. Therefore, manufacturers apply to suppliers for trade credit financing (deferred payment service). We assume that the initial capital of the manufacturer is $B$, the order quantity is $q_{T}$, and the wholesale price is $w_{T}$, so the manufacturer needs to finance $\left(w_{T} q_{T}-B\right)^{+}$from the supplier. The supplier provides revenue sharing contract $\left(w_{T}, \lambda, T\right)$ to the manufacturer, where $\lambda$ represents the revenue sharing proportion and $T$ represents the financial support (transfer payment) provided by the supplier to the manufacturer. The specific decisionmaking process is as follows. First, the supplier provides revenue sharing contract $(w, \lambda, T)$ to the manufacturer; the manufacturer then determines the order quantity $q_{T}$ and the low-carbon emission reduction level $k_{t T}$ according to the contract. At the end of the period, according to the contract, the manufacturer shall pay $1-\lambda$ of the income to the supplier, and the supplier shall transfer the payment fund $T$ to the manufacturer. Finally, the manufacturer pays back the loan amount $w_{T} q_{T}-B$. Therefore, in the TCF mode, the revenue function of the manufacturer can be expressed as follows:

$$
\pi_{T}^{m}=E\left[\lambda p \min \left\{D, q_{T}\right\}\right]+p_{e}\left[U-\left(e q_{T}-k_{t T}\right)\right]-\left(w_{T} q_{T}+\frac{1}{2} \tau k_{t T}^{2}-B\right)^{+}+T .
$$

Proposition 3. In TCF mode, when the supplier is given the sharing contract $\left(w_{T}, \lambda, T\right)$, the manufacturer's optimal order quantity $q_{T}$ and low-carbon emission reduction level $k_{T}$ are as follows:

$$
\left\{\begin{array}{l}
q_{T}^{*}=F^{-1}\left(\hat{y}_{2}\right)+\delta k_{t}, \\
k_{t T}^{*}=\frac{\delta\left(\lambda p-p_{e} e-w_{T}\right)+p_{e}}{\tau},
\end{array}\right.
$$

where $\hat{y}_{2}=\lambda p-p_{e} e-w_{T} / \lambda p$.

Proof. The manufacturer's expected profit expression can be written as follows:

$$
\pi_{T}^{m}=\lambda p\left[q_{T}-\int_{0}^{q_{T}-\delta k_{t T}} F(x) d x\right]+p_{e}\left[U-\left(e q_{T}-k_{t T}\right)\right]-\left(w_{T} q_{T}+\frac{1}{2} \tau k_{t T}^{2}-B\right)^{+}+T .
$$

Firstly, taking the first and second derivatives of $\pi_{T}^{m}$ with respect to $q_{T}$, we have the following: 


$$
\begin{aligned}
\frac{d \pi_{T}^{m}}{d q_{T}} & =\lambda p\left[1-F\left(q_{T}-\delta k_{t T}\right)\right]-p_{e} e-w_{T}, \\
\frac{d^{2} \pi_{T}^{m}}{d q_{T}^{2}} & =-\lambda p f\left(q_{T}-\delta k_{t T}\right) .
\end{aligned}
$$

Then, taking the first and second derivatives of $\pi_{T}^{m}$ with respect to $k_{t T}$, we can get the following:

$$
\begin{aligned}
\frac{d \pi_{T}^{m}}{d k_{t T}} & =\lambda p \delta F\left(q_{T}-\delta k_{t T}\right)+p_{e}-\tau k_{t T}, \\
\frac{d^{2} \pi_{T}^{m}}{d k_{t T}^{2}} & =-\lambda p \delta^{2} f\left(q_{T}-\delta k_{t T}\right)-\tau .
\end{aligned}
$$

Finally, the derivative of $d \pi_{T}^{m} / d q_{T}$ is taken with respect to $k_{t T}$, and we have the following:

$$
\frac{\partial^{2} \pi_{T}^{m}}{\partial q_{T} \partial k_{t T}}=\lambda p \delta\left[f\left(q_{T}-\delta k_{t T}\right)\right]
$$

Therefore, we can get the determinant $H\left(q_{T}, k_{t T}\right)=\lambda p \tau f\left(q_{T}-\delta k_{t T}\right)>0$. From $d^{2} \pi_{T}^{m} / d q_{T}^{2}<0$ and $H\left(q_{T}, k_{t T}\right)>0$, we can get that the Hessian matrices are negative definite, so we can judge that $\pi_{T}^{m}$ is jointly concave at points $q_{T}$ and $k_{t T}$. So, let $d \pi_{T}^{m} / d q_{T}=0$ and $d \pi_{T}^{m} / d k_{t T}=0$, and we can get the manufacturer's optimal order quantity and optimal emission reduction level.

From Proposition 3, we can see that when determining the optimal order quantity, manufacturers mainly consider wholesale price, revenue sharing ratio, product sale price carbon trading price, and carbon emission per unit product. When determining the low-carbon emission reduction level, manufacturers mainly consider the low-carbon preference coefficient of consumers, revenue sharing ratio, product sale price, carbon trading price, carbon emission per unit product, wholesale price, and low-carbon emission reduction cost coefficient.

Proposition 3 shows that manufacturer's order quantity is positively correlated with consumer's low-carbon preference coefficient and manufacturer's emission reduction level. Manufacturers' low-carbon emission reduction level is positively correlated with revenue sharing ratio, consumers' low-carbon preference, product sale price, and carbon trading price and is negatively correlated with low emission reduction cost coefficient.

Similarly, in the TCF mode, the revenue function of suppliers can be expressed as follows:

$$
\pi_{T}^{s}=\left(w_{T}-c\right) q_{T}+(1-\lambda) p\left[q_{T}-\int_{0}^{q_{T}-\delta k_{t T}} F(x) \mathrm{d} x\right]-T .
$$

Thus, based on backward induction, we can obtain the supplier's optimal wholesale price $w_{T}$, as shown in Proposition 4.

Proposition 4. In TCF mode, the supplier's optimal wholesale price $w_{T}$ is as follows:

$$
w_{T}^{*}=c-\frac{\lambda p q_{T} F^{2}\left(\hat{y}_{2}\right)}{f\left(\hat{y}_{2}\right)}-(1-\lambda) p\left[\bar{F}\left(q_{T}-\delta k_{t T}\right)\right],
$$

where $\hat{y}_{2}=\lambda p-p_{e} e-w_{T} / \lambda p$.

Proof. Supplier's expected revenue can be expressed as follows:

$$
\pi_{T}^{s}=\left(w_{T}-c\right) q_{T}+(1-\lambda) p\left[q_{T}-\int_{0}^{q_{T}-\delta k_{t T}} F(x) \mathrm{d} x\right] .
$$

By taking the first derivative of $\pi_{T}^{s}$ with respect to $w_{T}$, we can get the following:

$$
\frac{d \pi_{T}^{s}}{d w_{T}}=q_{T}+\frac{d q_{T}}{d w_{T}}\left(w_{T}-c\right)+(1-\lambda) p\left[\frac{d q_{T}}{d w_{T}}-F\left(q_{T}-\delta k_{t T}\right) \frac{d q_{T}}{d w_{T}}\right]
$$

Let equation (19) equal 0 , and we can get $w_{T}^{*}$.

From Proposition 4, we can see that suppliers mainly consider production cost, order quantity, revenue sharing ratio, product sale price, carbon trading price, and carbon emission per unit product when determining wholesale price. Proposition 4 shows that supplier's wholesale price is positively correlated with production cost and negatively correlated with order quantity and revenue sharing coefficient.

\section{Comparative Analysis}

In the previous section, the balancing strategies of suppliers and manufacturers in BCF and TCF patterns were analyzed, as shown in Table 2.
Proposition 5. It compares the manufacturer's optimal order quantity under BCF and TCF modes. When $p_{e}>\lambda w_{B}(1+R)-w_{T} /(1-\lambda) e$, we can get $q_{B}^{*}>q_{T}^{*}$; conversely, when $p_{e}<\lambda w_{B}(1+R)-w_{T} /(1-\lambda) e$, we have $q_{B}^{*}<q_{T}^{*}$.

Proof. In BCF mode, from $q_{B}^{*}=F^{-1}\left[p-p_{e} e-w_{B}(1+R)\right.$ $/ p]+\delta k_{t}$, we can get the following:

$$
F\left(q_{B}^{*}-\delta k_{t}\right)=\frac{p-p_{e} e-w_{B}(1+R)}{p} .
$$

In TCF mode, from $q_{T}^{*}=F^{-1}\left(\lambda p-p_{e} e-w_{T} / \lambda p\right)+\delta k_{t}$, we have the following:

$$
F\left(q_{T}^{*}-\delta k_{t}\right)=\frac{\lambda p-p_{e} e-w_{T}}{\lambda p} .
$$


TABLE 2: Equilibrium table of the financing mode.

\begin{tabular}{lc}
\hline BCF & TCF \\
\hline$q_{B}^{*}=F^{-1}\left(\hat{y}_{1}\right)+\delta k_{t B}$ & $q_{T}^{*}=F^{-1}\left(\hat{y}_{2}\right)+\delta k_{t T}$ \\
$k_{t B}^{*}=\left(\delta\left[p-p_{e} e-w_{B}(1+R)\right]+p_{e} / \tau(1+R)\right)$ & $k_{t T}^{*}=\left(\delta\left[\lambda p-p_{e} e-w_{T}\right]+p_{e} / \tau\right)$ \\
$w_{B}^{*}=c-p q_{B} F^{2}\left(\hat{y}_{1}\right) /(1+R) f\left(\hat{y}_{1}\right)$ & $w_{T}^{*}=c-\lambda p q_{T} F^{2}\left(\widehat{y}_{2}\right) / f\left(\widehat{y}_{2}\right)-(1-\lambda) p\left[\bar{F}\left(q_{T}-\delta k_{t T}\right)\right]$ \\
\hline
\end{tabular}

We make $\widehat{y}_{1}=F\left(q_{B}^{*}-\delta k_{t}\right)=p-p_{e} e-w_{B}(1+R) / p$, $\hat{y}_{2}=F\left(q_{T}^{*}-\delta k_{t}\right)=\lambda p-p_{e} e-w_{T} / \lambda p$.

Since $F\left(q-\delta k_{t}\right)$ is an increasing function of $q_{B}$, then, when $w_{T}>\widehat{w}$, we get $\widehat{y}_{1}>\widehat{y}_{2}$, that is, $q_{B}^{*}>q_{T}^{*}$; conversely, when $w_{T}<\widehat{w}$, we get $\hat{y}_{1}<\widehat{y}_{2}$, that is, $q_{B}^{*}<q_{T}^{*}$, where $\widehat{w}=\lambda p_{e} e+w_{B} \lambda(1+R)-p_{e} e$.

Proposition 5 shows that the order quantity of manufacturers mainly depends on the relationship between correlation coefficients. We take the wholesale price as the benchmark to measure. When the wholesale price $w_{T}>\widehat{w}$, the order quantity of the manufacturer is higher in BCF mode. On the contrary, when the wholesale price $w_{T}<\widehat{w}$, the manufacturer's order quantity is higher in TCF mode.

Proposition 6. By comparing the emission reduction level of manufacturers under BCF and TCF modes, we can get the following: when $p_{e}<\widehat{p}_{e}, k_{t B}^{*}>k_{t T}^{*}$; conversely, when $p_{e}>\widehat{p}_{e}$, $k_{t B}^{*}<k_{t T}^{*}$.

Proof. From $k_{t B}^{*}=\delta\left[p-p_{e} e-w_{B}(1+R)\right]+p_{e} / \tau(1+R)$, $k_{t T}^{*}=\delta\left[\lambda p-p_{e} e-w_{T}\right]+p_{e} / \tau$, compared with the carbon trading price as the benchmark, we can get the following: when $p_{e}<\widehat{p}_{e}, k_{t B}^{*}>k_{t T}^{*}$; conversely, when $p_{e}>\widehat{p}_{e}, k_{t B}^{*}<k_{t T}^{*}$, where

$\widehat{p}_{e}=\delta p-\delta(1+R)\left(w_{B}+\lambda p-w_{T}\right) / R-(1+R) \delta e+\delta e$.

Proposition 6 shows that when the carbon trading price $p_{e}>\widehat{p}_{e}$, the low-carbon emission reduction level under TCF mode is higher than that under BCF mode. On the contrary, when the carbon trading price $p_{e}<\widehat{p}_{e}$, the low-carbon emission reduction level in TCF mode is lower than the wholesale price in BCF mode.

Proposition 7. By comparing the wholesale price of suppliers under BCF and TCF models, we can get the following: when the manufacturer's revenue sharing coefficient $\lambda>\hat{\lambda}, w_{T}^{*}>w_{B}^{*}$; conversely, when $\lambda<\hat{\lambda}, w_{T}^{*}<w_{B}^{*}$.

Proof. According to the above solution, in BCF mode, $w_{B}^{*}=c-p q_{B} F^{2}\left(\widehat{y}_{1}\right) /(1+R) f\left(\hat{y}_{1}\right)$, and in TCF mode, $w_{T}^{*}=c-\lambda p q_{T} F^{2}\left(\hat{y}_{2}\right) / f\left(\hat{y}_{2}\right)-(1-\lambda) p\left[\bar{F}\left(q_{T}-\delta k_{t T}\right)\right]$.

Taking the manufacturer's revenue sharing coefficient as the benchmark for comparison, we can get the following: when the manufacturer's revenue sharing coefficient $\lambda>\hat{\lambda}$, $w_{T}^{*}>w_{B}^{*}$; conversely, when $\lambda<\hat{\lambda}, \quad w_{T}^{*}<w_{B}^{*}$, where $\widehat{\lambda}=\left[\left(q_{B} F^{2}\left(\hat{y}_{1}\right) / \quad(1+R) f\left(\hat{y}_{1}\right)\right)+\bar{F}\left(q_{T}-\delta k_{t T}\right)\right] /[\bar{F}($ $\left.\left.q_{T}-\delta k_{t T}\right)-\left(q_{T} F^{2}\left(\hat{y}_{2}\right) / f\left(\hat{y}_{2}\right)\right)\right]$,

$\widehat{y}_{1}=p-p_{e} e-w_{B}(1+R) / p, \hat{y}_{2}=\lambda p-p_{e} e-w_{T} / \lambda p$.

Proposition 7 shows that when the manufacturer's revenue sharing coefficient $\lambda>\widehat{\lambda}$, the wholesale price under TCF is higher than the wholesale price under BCF. When the manufacturer's revenue sharing coefficient $\lambda<\widehat{\lambda}$, the wholesale price under TCF is lower than that under BCF.

\section{Numerical Analysis}

In this section, the effectiveness of the two modes and the influence of key parameters are further analyzed through numerical simulation. This study selects the numerical analysis of a chemical enterprise, which chooses to invest in carbon capture and storage (CCS) technology to reduce carbon emission levels. The following parameters are set according to China Energy Statistical Yearbook, China Statistical Yearbook, and Research Institute on CCS Technology Investment. The specific parameters are as follows: the price per unit product is 1.5 yuan, the government carbon quota is 5 tons, and the carbon emission per unit product is $0.93 \mathrm{~kg}$. The unit price of carbon trading is 0.05 yuan, the initial capital is 2 million, and the carbon emission without CCS technology per unit product is $0.89 \mathrm{~kg}$. After CCS Technology Investment, the emission reduction level per unit is $0.58 \mathrm{~kg}$, and the low-carbon emission reduction cost coefficient is 0.6 . The wholesale price of raw materials per unit is 0.5 yuan. We suppose that consumer demand follows the uniform distribution of [0.1], the consumer low-carbon preference coefficient is 0.6 , the bank credit annual interest rate is 0.07 , the revenue sharing coefficient is 0.93 , the production cost per unit is 0.2 yuan, the low-carbon emission reduction cost coefficient is 0.6 , and the sum of financial risk cost and opportunity cost generated by asset mortgage of chemical enterprise per unit is 0.8 yuan. The amount of transfer payment from raw material suppliers to enterprise is 0.3 million.

As can be seen from Figure 2, under the two financing modes, manufacturers' income initially increases with the increase in low-carbon emission reduction level, but when the carbon emission reduction level reaches a certain value, manufacturers' income decreases with the increase in emission reduction level. This is mainly due to decreasing marginal consumer demand as carbon reduction levels continue to increase. In addition, we can also see that TCF mode can enable manufacturers to obtain higher income when the low-carbon emission reduction level is low. When carbon emission reduction level is high, BCF mode can enable manufacturers to obtain higher income. This mainly depends on the relationship between the profit shared by the manufacturer and the sum of the costs of bank interest, opportunity cost, and financial risk.

As can be seen from Figure 3, suppliers' income increases with the increase in carbon emission reduction level under the two financing modes, and this is mainly due to the increase in orders from manufacturers as the level of carbon reduction increases. At the same time, we can also see that in 


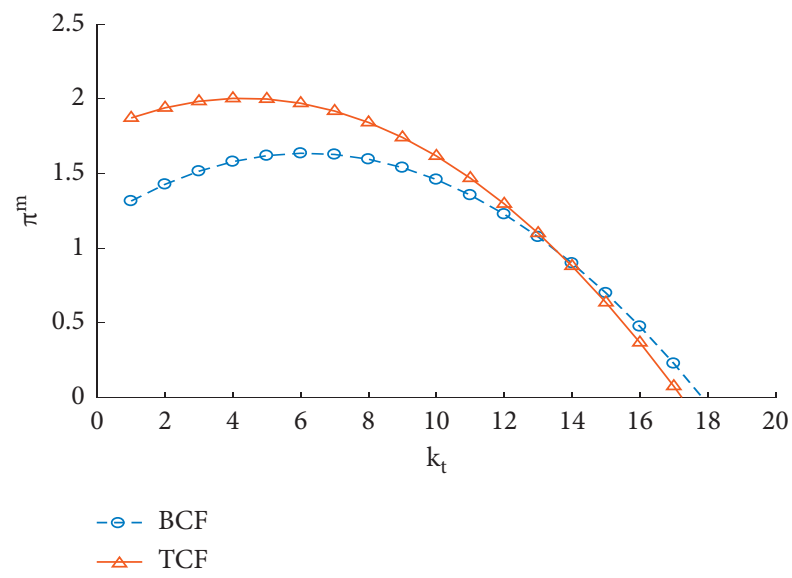

Figure 2: Influence of low-carbon emission reduction level on manufacturer's income.

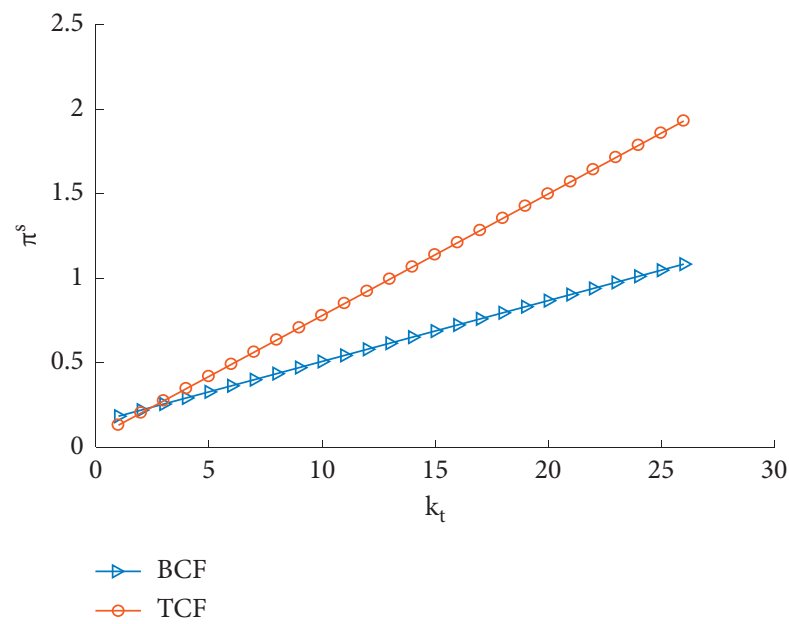

Figure 3: Impact of low-carbon emission reduction in supplier revenue.

TCF mode, suppliers' income is higher than that in BCF mode, which is mainly caused by the increase in manufacturers' order quantity in TCF mode than in BCF mode.

As can be seen from Figure 4, manufacturers' order quantity increases with the increase in low-carbon emission reduction level under the two financing modes. This is mainly because consumer demand increases with the improvement of carbon emission reduction level. In addition, it can also be seen that the manufacturer's order quantity under TCF mode is higher than that under BCF mode, which is mainly caused by the decrease in supplier's wholesale price.

As can be seen from Figure 5, we can see that the emission reduction level in BCF mode is higher than that in TCF mode. At the same time, we found that the emission reduction level of manufacturers increases with the increase in carbon trading price under the two financing modes, and this is mainly because, with the increase in carbon trading price, manufacturers will take the initiative to improve their emission reduction level for cost.

As can be seen from Figure 6, supplier wholesale price is sensitive to low-carbon emission reduction level under TCF mode. At first, the wholesale price of suppliers decreases

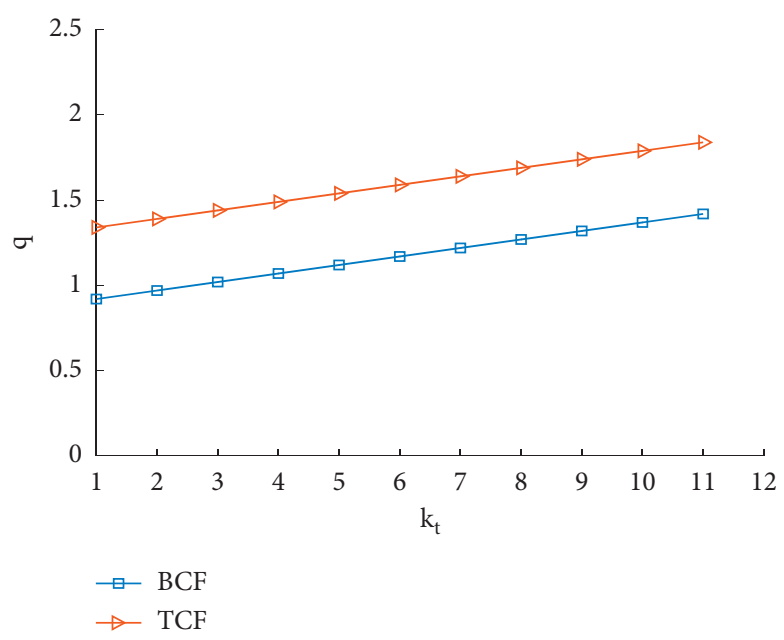

FIGURE 4: Influence of low-carbon emission reduction level on order quantity.

with the increase in low-carbon emission reduction level, but when the low-carbon level reaches a certain value, the wholesale price of suppliers increases with the increase in 


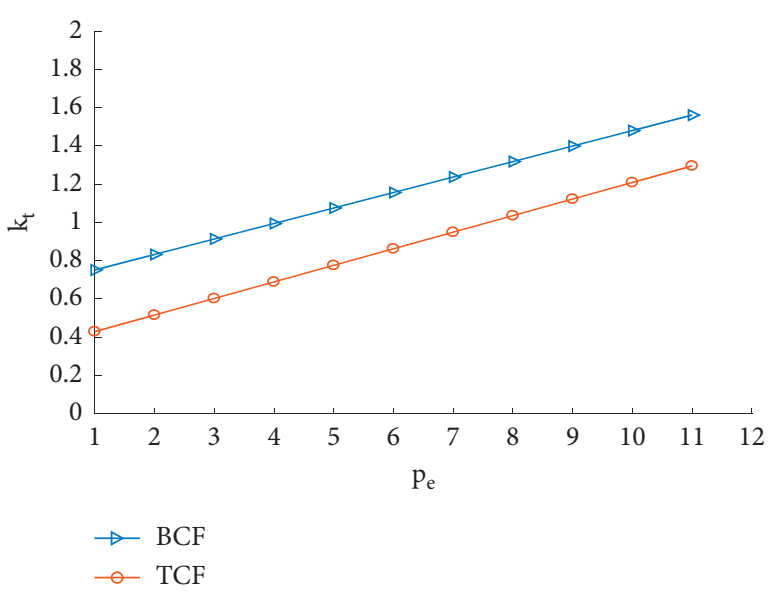

FIGURE 5: Influence of carbon trading price on low-carbon emission reduction level.

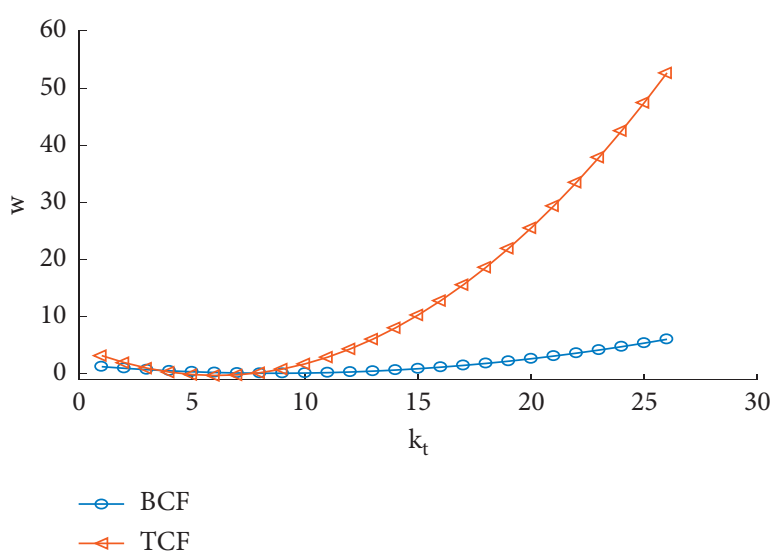

FIGURE 6: Influence of low-carbon emission reduction level on wholesale price.

emission reduction level. This is mainly because the manufacturer emission reduction input exceeds a certain value and the order quantity is reduced. In BCF mode, the wholesale price of suppliers is not greatly affected by the level of carbon emission reduction. This is mainly because, in $\mathrm{BCF}$ mode, the manufacturer's order quantity is relatively stable.

\section{Conclusions}

In this study, we study a supply chain financing system that is composed of well-funded suppliers and capital-constrained manufacturers facing uncertain demand. Different from previous studies, this study designs two financing models to analyze supply chain operations and finance decision considering the impact of carbon emission trading. We analyze the equilibrium strategies of the two finance modes and analyze the sensitivity of relevant parameters to illustrate the effectiveness of the two financing modes. We can draw the following conclusions.

Firstly, under certain conditions, manufacturers' emission reduction level has nothing to do with the government's carbon quota, but it is mainly affected by the carbon trading price. Secondly, for manufacturers, there is a threshold of carbon emission reduction level. When the emission reduction level is higher than the threshold, the manufacturer's income under BCF is higher than that under TCF. When below the threshold, the returns under TCF are better. Thirdly, for the supplier, BCF can make the manufacturer get more benefits when the manufacturer's emission reduction level is low. On the contrary, when the manufacturer's emission reduction level is high, the income can be higher under TCF.

The management implications of the above finding are significant. First, the government can optimize supply chain efficiency and low-carbon emission reduction by adjusting the carbon trading price. Second, suppliers can reduce wholesale prices and jointly reduce emissions to promote manufacturers' emission reduction investment to improve their own income. Third, manufacturers can choose different financing modes according to emission reduction level, and they will achieve a win-win situation with suppliers by determining appropriate emission reduction level.

However, this study still has some limitations. The study assumes that all information is the common knowledge of members in the supply chain, but information of members in the supply chain is often asymmetric in practice and could be an interesting direction for further study. In addition, we only consider the single application of GCF and TCF, but the study can be further extended to the combination of the two financing modes. For example, manufacturers can borrow money through TCF to obtain raw materials for production and borrow money from banks through GCF to invest in low-carbon emission reduction. It is more practical significant to derive equilibrium solutions and analyze the properties of equilibrium solutions. These are the important directions for our future research.

\section{Data Availability}

The data in this study are from a company in Shanghai, which chooses to invest in carbon capture and storage (CCS) technology to reduce carbon emission levels. The parameters are set according to China Stock Market \& Accounting Research Database, China Energy Statistical Yearbook, China Statistical Yearbook, and Research Institute on CCS Technology Investment.

\section{Conflicts of Interest}

The authors declare that they have no conflicts of interest.

\section{References}

[1] B. Zhang and L. Xu, "Multi-item production planning with carbon cap and trade mechanism," International Journal of Production Economics, vol. 144, no. 1, pp. 118-127, 2013.

[2] L. Li and F. Tao, "Research on the influencing factors of cooperative innovation based on dual-R\&D model," Science \& Technology Progress and Countermeasures, vol. 29, no. 8, pp. 1-4, 2012.

[3] Y. Yu, G. Huang, and X. Guo, "Financing strategy analysis for a multi-sided platform with blockchain technology," 
International Journal of Production Research, vol. 59, no. 15, pp. 4513-4532, 2021.

[4] X. Chen, "A model of trade credit in a capital-constrained distribution channel," International Journal of Production Economics, vol. 159, no. 1, pp. 347-357, 2015.

[5] I. Dobos, "The effects of emission trading on production and inventories in the Arrow-Karlin model," International Journal of Production Economics, vol. 93-94, pp. 301-308, 2005.

[6] Y. Qin, X. Cao, and L. Cao, "Research on supply chain operation strategy and coordination under carbon emission trading mechanism," Operations Research and Management Science, vol. 26, no. 3, pp. 36-42, 2017.

[7] S. Song, K. Govindan, L. Xu, P. Du, and X. Qiao, "Capacity and production planning with carbon emission constraints," Transportation Research Part E: Logistics and Transportation Review, vol. 97, no. 1, pp. 132-150, 2017.

[8] X. Xu, W. Zhang, P. He, and X. Xu, "Production and pricing problems in make-to-order supply chain with cap-and-trade regulation," Omega, vol. 66, no. 1, pp. 248-257, 2017.

[9] Q. Bai, Y. Gong, M. Jin, and X. Xu, "Effects of carbon emission reduction on supply chain coordination with vendor-managed deteriorating product inventory," International Journal of Production Economics, vol. 208, no. 7, pp. 83-99, 2019.

[10] M Mishra, S. K Hota, S. K Ghosh, and B Sarkar, "Controlling waste and carbon emission for a sustainable closed-loop supply chain management under a cap-and-trade strategy," Mathematics, vol. 8, 2020.

[11] B. Jing, X. Chen, and G. G. Cai, "Equilibrium financing in a distribution channel with capital constraint," Production and Operations Management, vol. 21, no. 6, pp. 1090-1101, 2012.

[12] J. Huang, W. Yang, and Y. Tu, "Financing mode decision in a supply chain with financial constraint," International Journal of Production Economics, vol. 220, 2019.

[13] E. Cao and M. Yu, "The bright side of carbon emission permits on supply chain financing and performance," Omega, vol. 88, no. 8, pp. 24-39, 2019.

[14] J. Huang, Q. Lu, and X. Chen, "Research on the value impact of buyer's guarantee mechanism in supplier financing," Journal of management science, vol. 23, no. 7, pp. 99-115, 2020.

[15] S. A. Yang and J. R. Birge, "Trade credit, risk sharing, and inventory financing portfolios," Manage Sci, vol. 64, no. 8, pp. 3469-970, 2018.

[16] J. N. Beka, B. Nguema, G. Bi, Z. Ali, and Y. Ke, "Exploring the factors influencing the adoption of supply chain finance in supply chain effectiveness: evidence from manufacturing firms," Journal of Business \& Industrial Marketing, vol. 36, no. 5, pp. 706-716, 2021.

[17] J. Shi, Q. Du, F. Lin, K. K. Lai, and T. C. E. Cheng, "Optimal financing mode selection for a capital-constrained retailer under an implicit bankruptcy cost," International Journal of Production Economics, vol. 228, 2020.

[18] P. Kouvelis and W. Zhao, "Financing the newsvendor: Supplier vs. bank, and the structure of optimal trade credit contracts," Operations research, vol. 60, no. 3, pp. 566-580, 2012.

[19] G. G. Cai, X. Chen, and Z. Xiao, “The roles of bank and trade credits: Theoretical analysis and empirical evidence," Production and Operations Management, vol. 23, no. 4, pp. 583-598, 2014.

[20] B. Li, S.-M. An, and D.-P. Song, "Selection of financing strategies with a risk-averse supplier in a capital-constrained supply chain," Transportation Research Part E: Logistics and Transportation Review, vol. 118, no. 10, pp. 163-183, 2018.
[21] Y.-W. Zhou, B. Cao, Y. Zhong, and Y. Wu, "Optimal advertising/ordering policy and finance mode selection for a capital-constrained retailer with stochastic demand," Journal of the Operational Research Society, vol. 68, no. 12, pp. 1620-1632, 2017.

[22] B. Mandal, B. K. Dey, S. Khanra, and B. Sarkar, "Advance sustainable inventory management through advertisement and trade-credit policy," RAIRO - Operations Research, vol. 55, no. 1, pp. 261-284, 2021.

[23] B. Sarkar, B. K. Dey, M. Sarkar, S. Hur, B. Mandal, and V. Dhaka, "Optimal replenishment decision for retailers with variable demand for deteriorating products under a tradecredit policy," RAIRO - Operations Research, vol. 54, no. 6, pp. 1685-1701, 2020.

[24] A. H. M Mashud, H. M Wee, B Sarkar, and Y. H. C Li, "A sustainable inventory system with the advanced payment policy and trade-credit strategy for a two-warehouse inventory system," Kybernetes, vol. 50, 2020.

[25] W. Ahmed, M. Moazzam, B. Sarkar, and S. Ur Rehman, "Synergic Effect of Reworking for Imperfect Quality Items with the Integration of Multi-Period Delay-in-Payment and Partial Backordering in Global Supply Chains," Engineering, vol. 7, no. 2, pp. 260-271, 2021.

[26] A. H. M Mashud and B Sarkar, "Retailer's joint pricing model through an effective preservation strategy under a trade-credit policy," RAIRO-Operations Research, vol. 55, 2021.

[27] A. A Shaikh, S. C Das, A. K Bhunia, and B Sarkar, "Decision support system for customers during availability of trade credit financing with different pricing situations," RAIROOperations Research, vol. 55, 2021.

[28] S. R Singh, D. Yadav, B. Sarkar, and M. Sarkar, "Impact of energy and carbon emission of a supply chain management with two-level trade-credit policy," Energies, vol. 14, no. 6, 2021.

[29] S. An, B. Li, D. Song, and X. Chen, "Green credit financing versus trade credit financing in a supply chain with carbon emission limits," European Journal of Operational Research, vol. 292, no. 1, pp. 125-142, 2021.

[30] X. Zhang and H. Yousaf, "Green supply chain coordination considering government intervention, green investment, and customer green preferences in the petroleum industry," Journal of Cleaner Production, vol. 246, 2020.

[31] D. Z. Zhao, B. Y. Yuan, and C. M. Xu, "Dynamic optimization of vertical cooperation emission reduction in low-carbon supply chain," control and decision making, vol. 7, pp. 13401344, 2014.

[32] S. Xu and L. Fang, "Partial credit guarantee and trade credit in an emission-dependent supply chain with capital constraint," Transportation Research Part E: Logistics and Transportation Review, vol. 135, 2020. 